\title{
Parkinson's disease; Its Occurrence and Identification of Risk Factors in Khyber Pakhtunkhwa, Pakistan
}

\author{
Saleem-Ur-Rahman \\ Student, Department of Biotechnology, University of Malakand \\ Chakdara, Dir (L), Khyber Pakhtunkhwa, Pakistan \\ E-mail: saleemurrrahman20@gmail.com \\ Ikram Ilahi (Corresponding author) \\ Assistant Professor, Department of Zoology, University of Malakand \\ Chakdara, Dir (L), Khyber Pakhtunkhwa, Pakistan \\ E-mail: ikramilahi@uom.edu.pk
}

\begin{abstract}
Suliman Khan
Department of Biotechnology, University of Malakand

Chakdara, Dir (L), Khyber Pakhtunkhwa, Pakistan

E-mail: suliman83qau@gmail.com
\end{abstract}

\begin{abstract}
Ayaz Ali Khan
Assistant Professor, Department of Biotechnology, University of Malakand

Chakdara, Dir (L), Khyber Pakhtunkhwa, Pakistan

E-mail: lalatejan@gmail.com
\end{abstract}

Muhammad Zuhaib Khan

Student, Department of Biotechnology, University of Malakand

Chakdara, Dir (L), Khyber Pakhtunkhwa, Pakistan

E-mail: Zuhaib_bt@yahoo.com

Received: November 6, 2012 Accepted: November 20, 2012

doi:10.5296/jbls.v4i1.2625 URL: http://dx.doi.org/10.5296/jbls.v4i1.2625 


\section{Abstract}

The present survey aimed to study the age, gender, residency and occupation wise occurrence of Parkinson's disease in Khyber Pakhtunkhwa (KPK), Pakistan. The Parkinson's patients, who were visiting Neurology Department, Postgraduate Medical Institute, Lady Reading Hospital Peshawar, were interviewed and the information were recorded in questionnaires. The age limit of patients was 30 to 80 years. The data obtained was analyzed for gender, age, occupation and residency wise occurrence of Parkinson's disease. The survey showed that Parkinson's disease is more common in male than in female. The elderly age group (61-70 years) and farmers were more affected. The disease was more common in rural areas than in urban. The current investigation analyzes the pattern of Parkinson's disease and gives information about the related factors in the province.

Keywords: Occurrence, Gender, Age groups, Occupation, Residency

\section{Introduction}

Parkinson's disease (PD) is one of the most common neurological disorders (Champo et al., 2010). The symptoms of the disease include depression, Sleep disturbances (Pal et al., 2004) bradykinesia, hypokinesia, resting tremor, rigidity and postural reflexes (Veldman et al., 1998). It effects about 1-2\% of the population (Reichmann et al., 2009). Parkinson's disease is age dependent and happens rarely before the age of 50 years and a sharp increase of the incidence is seen after the age of 60 years (De Lau and Breteler, 2006). Due to toxicant exposure, head trauma, neuroprotection, mitochondrial dysfunction, and X-linkage of genetic factors; Parkinson's disease was found with higher rate in males than in females (Wooten et al., 2004). The risk of Parkinson's diseases is related to the use of well water, farming and contact with pesticides (Drozdzik et al., 2003) i.e. 1-methyl-4-phenyl-1, 2, 3, 6-tetrahydropyridine (MPTP) induces Parkinsonism in humans. Parkinson's disease is due to selective degeneration of dopaminergic neurons of the substantia nigra and formation of Lewy bodies (Betarbet et al., 2000), however the genetic transformation of the disease is rare (Naught et al., 2001). Some studies showed that the risk of PD is inversely associated with smoking (Martyn and Osmond, 1995) due to Monoamine Oxidase Type B (MAO-B) inhibitor in the smoker body cells (Veldman et al., 1998). According to Fall et al. (1996), the number of Parkinson's patients out of 10000 individuals was 57 in China, 347 in USA, 160 in Netherland and 115 in Sweden. About 80 cases of Parkinson's disease were reported in Sindh, Pakistan, during 2006 (Khealani and Baig, 2006). However no survey has yet been conducted on the occurrence of Parkinson's disease in province, Khyber Pakhtunkhwa (KPK), Pakistan. The present survey aimed to study the age, gender, residency and occupation wise occurrence of Parkinson's disease in Khyber Pakhtunkhwa (KPK), Pakistan.

\section{Materials and Methods}

During the present study, the data of Parkinson's patients were collected from Neurology Department, Postgraduate Medical Institute, Lady Reading Hospital Peshawar, Pakistan. The data included information about the occurrence of Parkinson's disease in male and female individuals, married and unmarried persons, and also in persons of different ages, residencies, 


\section{Macrothink}

Journal of Biology and Life Science

ISSN 2157-6076

2013, Vol. 4, No. 1

and of different occupations. During this study, attempts were made to collect information about clinical features and intellectual loss in patients with Parkinson's disease. For the collection of data, a printed questionnaire was designed which included the name, gender, age, marital status, residency, occupation, and other particulars of Parkinson's patients.

\section{Data collection}

The data was collected during March, 2011 till July, 2011, from Neurology Department, Postgraduate Medical Institute, Lady Reading Hospital Peshawar, Pakistan. Prior permission was granted by the Hospital administration for collection of data from Parkinson's patients. A written unsent was also signed from patients before taking interviews. Thirty patients were interviewed and data was recorded on printed questionnaires. These patients belonged to different parts of Khyber Pakhtunkhwa (KPK) who visited Lady Reading Hospital for diagnosis and treatment. Among these; twenty PD positive patients were interviewed in neurology ward while ten in other wards of the hospital. Mostly the data was analyzed in percentage. Linear regression analysis of SPSS 16 software was used for determining the association of Parkinson's disease with the age.

\section{Results}

\subsection{Gender and Age Wise Occurrence of Parkinson's Disease}

The occurrence of Parkinson's disease was greater in males than in females (Figure 1). Age wise occurrence of Parkinson's disease was also studied. Maximum Parkinson's patients (56\%) were belonging to the age group above 60 years. Minimum Parkinson's patients (10\%) were in the age group 31-40 years. The data showed a linear relationship of the age with the occurrence of Parkinson's disease (Table 1).

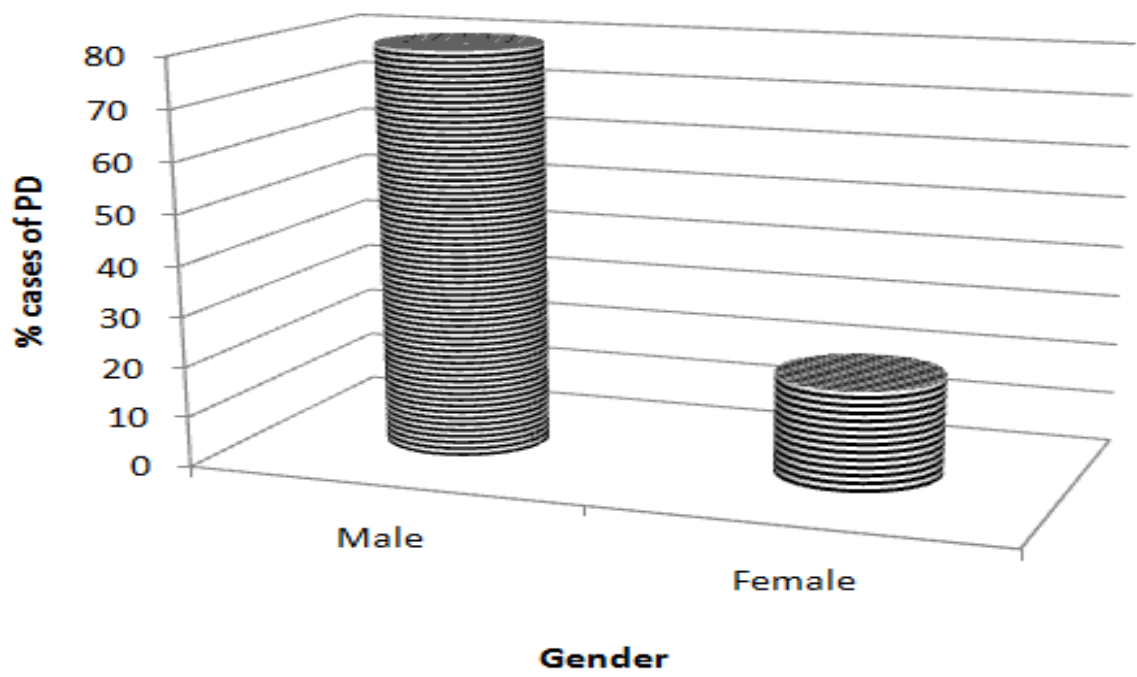

Figure 1. Gender wise occurence of Parkinson' s disease (PD) 
Table 1. Analysis of relationship between the age and the occurrence of PD.

\begin{tabular}{|c|c|c|c|}
\hline Age Groups (Years) & $\begin{array}{c}\text { Percentage of } \\
\text { P D }\end{array}$ & $\begin{array}{r}\text { R Square } \\
\text { Value }\end{array}$ & Significance \\
\cline { 1 - 2 } $31-40$ & 10 & & \\
\cline { 1 - 2 } $41-50$ & 10 & \multirow{2}{*}{0.92} & 0.041 \\
\cline { 1 - 2 } $51-60$ & 23 & & \\
\hline $61-80$ & 56 & & \\
\hline
\end{tabular}

PD-Parkinson's disease

\subsection{Clinical Features of Parkinson's Patient}

The clinical features of Parkinson's patients which were inquired from their physicians included depression, anxiety tremors in their arms, bradykinesia, rigidity in their muscles, shuffling gait, constipation, loss of sleep, excessive sweating, excessive salivation, persistent pain in their neck, swallowing difficulty, had dry skin and general pain in their whole body (Table 2).

Table 2. Clinical features of Parkinson’s disease

\begin{tabular}{|l|l|c|l|}
\hline S. No & Clinical symptoms & Frequency of Occurrence & Percentage \\
\hline 01 & Tremors & 28 & 93.33 \\
\hline 02 & Bradykinesia (slowness in voluntary moment) & 26 & 86.67 \\
\hline 03 & Rigidity or stiff muscles & 19 & 63.33 \\
\hline 04 & Shuffling gait(short rapid steps) & 20 & 66.67 \\
\hline 05 & Constipation & 12 & 40.00 \\
\hline 06 & Depression & 19 & 63.33 \\
\hline 07 & Insomnia (loss of sleep) & 08 & 26.67 \\
\hline 08 & Sweating & 08 & 26.67 \\
\hline 09 & Salivation & 10 & 33.33 \\
\hline 10 & Persistent neck pain & 06 & 20.00 \\
\hline 11 & Difficulty in swallowing & 04 & 13.33 \\
\hline 12 & Anxiety & 11 & 36.67 \\
\hline 13 & Dry skin on face and on scalp & 01 & 3.33 \\
\hline 14 & Soft whispery voice & 02 & 6.67 \\
\hline 15 & Pain & 08 & 26.67 \\
\hline
\end{tabular}

\subsection{Intellectual Loss and Response to Questions in Parkinson’s Patients}

In each of the age groups of 31-40 and 41-50 years, 3.33\% patients were suffering from memory loss and mental abnormality. The highest (16.67\%) memory loss was in each of the age groups of 51-60, and 61-70 years. The highest mental abnormality was in the age groups of 51-60 and 61-70 years (table 3). Most of the patients having slow response to questions were in the age group 61-70 years (Table 3). 


\section{Macrothink}

Journal of Biology and Life Science ISSN 2157-6076 2013, Vol. 4, No. 1

Table 3. Intellectual loss and response to questions in Parkinson's patients

\begin{tabular}{|c|c|c|c|c|c|c|}
\hline \multirow{2}{*}{$\begin{array}{c}\text { Age } \\
\text { groups } \\
\text { (years) }\end{array}$} & \multicolumn{3}{|c|}{ Intellectual Loss } & \multicolumn{3}{|c|}{ Response to Questions } \\
\hline & $\begin{array}{c}\text { Memory } \\
\text { Loss }\end{array}$ & $\begin{array}{c}\text { Mental } \\
\text { Loss }\end{array}$ & $\begin{array}{c}\text { Both Mental and } \\
\text { Memory Loss }\end{array}$ & $\begin{array}{c}\text { Slow } \\
\text { Response }\end{array}$ & $\begin{array}{c}\text { Quick } \\
\text { Response }\end{array}$ & $\begin{array}{l}\text { Moderate } \\
\text { Response }\end{array}$ \\
\hline $31-40$ & $3.33 \%$ & $3.33 \%$ & $3.33 \%$ & $3.33 \%$ & $3.33 \%$ & $3.33 \%$ \\
\hline $41-50$ & $3.33 \%$ & 0 & 0 & $6.6 \%$ & 0 & $3.33 \%$ \\
\hline $51-60$ & $16.67 \%$ & 0 & 0 & $6.6 \%$ & $3.33 \%$ & $13.32 \%$ \\
\hline $61-70$ & $16.67 \%$ & 0 & 0 & $9.99 \%$ & $3.33 \%$ & $13.32 \%$ \\
\hline $71-80$ & $10 \%$ & $6.6 \%$ & $6.6 \%$ & $6.6 \%$ & 0 & $9.99 \%$ \\
\hline
\end{tabular}

\subsection{Parkinson's Patients, Occupations and Addictions}

In the current study, $47 \%$ Parkinson's patients were farmers, $23.52 \%$ drivers, $11.76 \%$ shopkeepers, $11.76 \%$ labors and 5.88\% Parkinson's patients were teachers (Figure 2). Among the_Parkinson's patients, $13.3 \%$ were smokers and $86.7 \%$ were non-smokers. Similarly $26.6 \%$ Parkinson's patients were using snuff and $73.4 \%$ patients were non-snuff users.

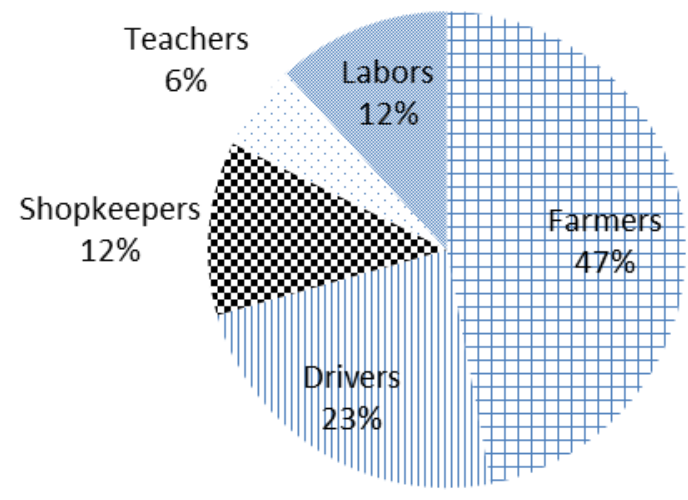

Figure 2. Occupation wise occurrence of Parkinson's disease

\subsection{Residency and Marital Status Wise Occurrence of the Parkinson’s Disease}

In the current study, $63.33 \%$ patients were from rural areas and $36.67 \%$ patients from urban areas (Table 4). In both the areas, maximum Parkinson's patients (20\%) were in the age group of $61-70$ years. During the survey, $93.34 \%$ patients were married and $6.66 \%$ were unmarried (Table 4). 
Table 4. Marital Status and Residency wise occurrence of Parkinson’s disease

\begin{tabular}{|c|c|c|c|c|c|c|c|c|}
\hline \multirow{3}{*}{ Age Groups (Years) } & \multicolumn{8}{|c|}{$\begin{array}{c}\text { Number of Patients } \\
\text { Total }=30 \text {, Male }=24 \text {, Female }=06 .\end{array}$} \\
\hline & \multicolumn{2}{|c|}{ Married } & \multicolumn{2}{|c|}{ Unmarried } & \multicolumn{2}{|c|}{ Rural } & \multicolumn{2}{|c|}{ Urban } \\
\hline & Number & $\%$ & Number & $\%$ & Number & $\%$ & Number & $\%$ \\
\hline $31-40$ & 3 & $10.00 \%$ & 0 & $0.00 \%$ & 3 & $10.00 \%$ & 0 & $0.00 \%$ \\
\hline $41-50$ & 3 & $10.00 \%$ & 0 & $0.0 \%$ & 1 & $3.33 \%$ & 2 & $6.67 \%$ \\
\hline $51-60$ & 6 & $20.00 \%$ & 1 & $3.33 \%$ & 4 & $13.33 \%$ & 3 & $10.00 \%$ \\
\hline $61-70$ & 11 & $36.67 \%$ & 1 & $3.33 \%$ & 6 & $20.00 \%$ & 6 & $20.00 \%$ \\
\hline $71-80$ & 5 & $16.67 \%$ & 0 & $0.00 \%$ & 5 & $16.67 \%$ & 0 & $0.00 \%$ \\
\hline Total & 28 & $93.33 \%$ & 2 & $6.67 \%$ & 19 & $63.33 \%$ & 11 & $36.67 \%$ \\
\hline
\end{tabular}

\section{Discussions}

During the present study, the data of Parkinson's patients were collected from Neurology Department, Postgraduate Medical Institute, Lady Reading Hospital Peshawar, Pakistan. The present survey provided information about the gender wise, age wise, occupation wise, marital status wise and residency wise occurrence of Parkinson's disease in Khyber Pakhtunkhwa, Pakistan.

According to the present survey, the incidence of Parkinson's disease is greater in males (80\%) than in females (20 \%). The higher occurrence of PD in male may be due to toxicant exposure, head trauma (Veldman et al 1998), neuroprotection by estrogen, mitochondrial dysfunction and X-linkage of genetic risk factors (Wooten et al., 2004). The present results is also in an agreement with Falcone et al. (2011), Wooten et al. (2004), Khealani et al. (2006) and Eeden (2003).

During the present survey maximum Parkinson's patients were belonging to age group above 60 years which showed a correlation between age and the occurrence of the Parkinson's disease. Khatri et al. (2009) and Eeden et al. (2003) also reported that the occurrence of Parkinson's disease increases with age.

Occupation wise survey showed that maximum Parkinson's patients belong to farming. This is correlated with the study of Tanner and Aston (2000) and Olanow and Tatton (1999) who concluded that Parkinson's disease is common in farmers.

During the survey, no correlation of the occurrence of Parkinson's disease with the use of tobacco was observed. The Veldman et al. (1998), Martyn and Osmond (1995), and Miller and Das (2007) also reported that the occurrence of Parkinson's disease is not associated with the use of tobacco.

Among the Parkinson's patients, the most frequently occurring symptoms were tremor (93.33\%), bradykinesia (86.67\%) and depression (63.33\%). Other symptoms occurred less frequently. The present results correlate with the reports of Aarsland et al. (1999), and Khealani 
and Baig (2006).

Marital status wise survey showed that most of the Parkinson's patients are old age and married. This is correlated with the results of Falcone et al. (2011). Residency wise survey showed that Parkinson's disease is more common in rural areas as compared to urban areas. This is correlated with Tanner and Aston (2000).

From the whole population (now not known) of the province Khyber Pakhtunkhwa, only 30 patients were visiting Lady Reading Hospital (LRH), Peshawar, Pakistan. There are reports about the occurrence of Parkinson's disease in China (57 per 100000), USA (347 per 100000), Netherland (160 per 100000) and Sweden (115 per 100000) (Fall et al 1996).

\section{Conclusion}

From the current survey it was concluded that the incidence of Parkinson's disease is greater in males than in females and is correlated with age. The worse effect of the disease is tremors and walking difficulty. The disease mostly occurs in farmers and in rural areas.

\section{Limitations}

During the present survey, the hospitals of the other provinces of the country have not been visited for collection of data from Parkinson's patient. There is the possibility that some Parkinson's patients of the province Khyber Pakhtunkhwa may visit the hospitals of other provinces. Therefore further study is required for correct estimation of the incidence of Parkinson's disease in different genders, age groups, residencies and occupations.

\section{Acknowledgements}

We are very thankful to Dr. Adnan (Incharge Department of Neurology) and Dr. Hussain Ahmad, Lady Reading Hospital Peshawar, Pakistan, for helping us in this survey.

\section{References}

Aarsland, D., Larsen, J. P., Lim, N. G., Janvin, C., Karlsen, K., Tandberg, E., \& Cummings, J. L. (1999). Range of neuropsychiatric disturbances in patients with Parkinson's disease. Journal of Neurology Neurosurgery and Psychiatry, 67, 492-496.

http://dx.doi.org/10.1136/jnnp.67.4.492

Betarbet, R., Sherer, T. B., Mackenzie, G., Osuna, M., Panov, A. V., \& Greenamyre, J. T. (2000). Chronic systemic pesticide exposure reproduces fetures of Parkinson's disease. Nature neuroscience, 3(12).

Champo, L. E. I. A., Wekking, E. M., Spliethoff-Kamminga, N. G. A., Cessie, S. L., \& Roos, R. A. C. (2010). The benefits of a standarized patient education program for patients with Parkinson's disease and their caregivers. Parkinsonism and related disorders, 16, 89-95. http://dx.doi.org/10.1016/j.parkreldis.2009.07.009

De Lau, L. M. L., \& Breteler, M. M., (2006). Epidemiology of Parkinson's disease. Lancet Neurology, 5, 525-535. http://dx.doi.org/10.1016/S1474-4422(06)70471-9 
Drozdzik, M., Bialecka, M., Mysliwiec, K., Honczarenko, K., Kiewicz, J., \& Sych, Z. (2003). Polymorphism in the P-glycoprotien drug transporter MDR1 gene a possible link between environmental and genetic factors in Parkinson's disease. Pharmacogenetics, 13(5), 259-263. http://dx.doi.org/10.1097/00008571-200305000-00004

Eeden, S. K. V. D., Tanner, C. M., Bernstein, A. L., Fross, R. D., Leimpeter, A., Bloch, D. A., \& Nelson, L. M. (2003). Incidence of Parkinson's disease: Variation by age, gender, and race/ethnicity. Amirican Journal Epidemiology, 157(11), 1015-1022.

http://dx.doi.org/10.1093/aje/kwg068

Falcone, D. C., Wood, E. C., Xie, S. X., Siderowf, A., \& Deerlin, V. M. V. (2011). Genetic Testing and Parkinson's Disease: Assessment of Patient Knowledge, Attitudes, and Interest. Journal Genetic Counsel, DOI 10.1007/s10897-011-9362-0.

Fall, P. A., Axelson, O., Fredriksson, M., Hansson, G., Lindrall, B., Olsson, J. E., \& Granerus, A. K. (1996). Age standardized incidence and Prevelance of Parkinson's disease in a Swedish Community. Journal of Clinical Epidemiology, 49(6), 637-641.

http://dx.doi.org/10.1016/0895-4356(96)00003-0

Khatri, I. A., \& Chaudhry, U. S. (2009). Parkinson's disease . Pakistan Journal of Neurological Sciences, 4(1), 33-43.

Khealani, B. A., \& Baig, S. M. (2006). Clinical spectrum of Parkinson's disease from Pakistan. Singapore Medical Journal, 47(12),1075.

Martyn, C. N., \& Osmond, C. (1995). Parkinson's disease and the environment in early life. Journal of the Neurological Sciences, 132, 201-206.

http://dx.doi.org/10.1016/0022-510X(95)00148-U

Miller, L. R., \& Das, S. K. (2007). Cigarette Smoking and Parkinson's Disease. EXCLI, 6: 93-99 - ISSN, 1611-2156.

Naught, K. S. P. M., Olanow, C. W., Halliwell, B., Isacson, O., \& Jenner, P. (2001). Failure of the ubiquitin proteasome system in Parkinson’s disease. Nature Reviews Neuroscience, 2.

Olanow, C. W., \& Tatton, W. G. (1999). Etiology and pathogenesis of Parkinson's disease.

Annual Review of Neurosciences, 22, 123-44.

http://dx.doi.org/10.1146/annurev.neuro.22.1.123

Pal, P. K., Thennarasu, K., Fleming, J., Schulzer, M., Brown, T., \& Calned, S. M. (2004). Nocturnal sleep disturbances and day time dysfunction in patients with Parkinson's disease and in their caregivers. Parkinsonism and related disorders, 10, 157-168. http://dx.doi.org/10.1016/j.parkreldis.2003.11.002

Reichmann, B. A. J., Schneider, C., \& Lohle, M. (2009). Non-motor features of Parkinson's disease: depression and dementia. Parkinsonism and related disorders, 15S3: S87-S92.

Tanner, C. M., \& Aston, D. A. (2000). Epidemiology of Parkinson's disease and akinetic syndromes. Current Opinion in Neuroogyl, 13, 427-430. 
http://dx.doi.org/10.1097/00019052-200008000-00010

Veldman, B. A. J., Wijn, A. M., Knoers, N., Praamstra, P., \& Horstink, M. W. I. M. (1998). Genetic and environmental risk factors in Parkinson's disease. Clinical Neurology and Neurosurgery, 100, 15-26. http://dx.doi.org/10.1016/S0303-8467(98)00009-2

Wooten, G. F., Currie, L. J., Bovbjerg, V. E., Lee, J. K., \& Patrie, J. (2004). Are men at greater risk for Parkinson's disease than women. Journal of Neurology Neurosergery and Psychiatry, 75, 637-639. http://dx.doi.org/10.1136/jnnp.2003.020982

\section{Copyright Disclaimer}

Copyright reserved by the author(s).

This article is an open-access article distributed under the terms and conditions of the Creative Commons Attribution license (http://creativecommons.org/licenses/by/3.0/). 